\title{
Sensitivity Improvement of PtSi/Porous Si Schottky Diode Gas Sensors
}

\author{
Mahdi Nazari and Saeid Khatami* \\ Amirkabir University of Technology, Department of Electrical Engineering, \\ Hafez Street, Tehran 1591634311, Iran
}

(Received November 14, 2011; accepted May 11, 2012)

Key words: Schottky diode, electric field, gas sensor, breakdown voltage, porous silicon

In this investigation, PtSi/porous n-Si Schottky diode gas sensors on $\langle 100\rangle$ n-type $\mathrm{Si}$ wafers were designed and fabricated, and their sensitivities to various concentrations of certain polar gases such as $\mathrm{CO}$ and nonpolar gases such as $\mathrm{CO}_{2}$ were investigated at room temperature and compared with experimental data reported by others. The main objective of this work was to improve the sensitivity of these sensors to the aforementioned gases. These diodes operate at reverse bias mode at the breakdown region. The presence of certain gases inside the pores changes the breakdown voltages of the diodes, and the shift in the breakdown voltage is mapped into the gas concentration. Sensitivity is enhanced when the produced electric field due to the physical presence of the gas molecules inside pores is large enough to affect the Schottky reverse bias voltage. The porosity level and pores' geometry are determined to be key factors in improving the sensitivities of these sensors. The sensors fabricated in this work were able to sense $80 \mathrm{ppm} \mathrm{CO}$ gas and $40 \mathrm{ppm} \mathrm{CO}_{2}$ gas in air, which were about 10-20 ppm or about $20 \%$ smaller than those reported by others. On the basis of the data obtained in this investigation, it is possible that these diodes can respond to much smaller concentrations of $\mathrm{CO}$ and $\mathrm{CO}_{2}$ in air if the porosity level and pores' geometry are optimized.

\section{Introduction}

Gas detection by PtSi/porous n-Si Schottky junction and change in electric field in the presence of certain gases have been investigated by several researchers. ${ }^{(1-4)}$ In principle, a selected gas can react with the metal and change the Schottky barrier height, which in turn affects the $I-V$ characteristics of the junction. This is mostly a high-temperature process that involves chemical reactions. The operational basis of $\mathrm{PtSi} /$ porous $\mathrm{n}-\mathrm{Si}$

"Corresponding author: e-mail: khatami@aut.ac.ir 
Shottky junctions as a gas detector is physical in nature and occurs at room temperature.

Polar gases such as $\mathrm{CO}$ have an internal dipole moment. It is believed that when a polar gas fills the pores of a PtSi/porous n-Si diode, its dipole moments line up with the electric field lines in the PtSi depletion region. This will cause an increase in the net electric field and, consequently, a decrease in the breakdown voltage of these diodes. In contrast, gases without dipole moment such as $\mathrm{CO}_{2}$ can replace the gas content inside the pores and cause an increase in the breakdown voltage of these diodes. These diodes exhibit high sensitivity to variations in gas concentration.

The breakdown-type behavior of PtSi/porous $\mathrm{n}-\mathrm{Si}$ junctions has been attributed to the single-electron effect and subsequent avalanche multiplication mechanisms. ${ }^{(1,2,5)}$ In short, the single electron effect is based on the fact that it takes an appreciable amount of energy to send an electron into a structure with a very small capacitance. For instance, for a very small structure whose capacitance $C$ is $10^{-18} \mathrm{~F}$, according to the $Q=C V$ relation, it takes the energy of $0.16 \mathrm{eV}$ to send an electron into this island. Alternatively, a single electron maintains a voltage of $0.16 \mathrm{~V}$ on this capacitor. Both mechanisms are caused by the large fringing electric fields developed at sharp edges of the pores. These electric fields have been analyzed using numerical methods, and the increase in the electric field by orders of magnitude (compared with nonporous samples) has been verified, and the depletion capacitances of the Schottky junctions have been calculated to be on the order of $10^{-19}$ to $10^{-20} \mathrm{~F}^{(5)}$ At such small capacitances, the Coulomb blockade phenomenon or single electron effect becomes important even at room temperature. Therefore, our main approach to improve the sensitivity of the PtSi/porous n-Si diodes was to increase the percent porosity of the Si substrate and to change the structure of the pores. This in turn required careful changes in the diameter (on top) and depth of the pores.

\section{Experimental}

In this work, $\langle 100\rangle$-oriented n-type silicon wafers with a resistivity range of $\rho=$ $3.6-5.4 \Omega \cdot \mathrm{cm}$ were used. Our investigation has shown that lower substrate impurity concentrations to a certain extent can cause an increase in the percent porosity of the substrate. Silicon was made porous electrochemically using (HF:ethanol:DI) solution when exposed to UV light. The electrolyte solution to obtain porous Si was composed of high-purity $\mathrm{HF}$ in $60 \%$ aqueous solution diluted in ethanol $\left(\mathrm{C}_{2} \mathrm{H}_{5} \mathrm{OH}\right)$ at different concentrations. The dilution in ethanol was necessary owing to the hydrophobic nature of the clean silicon surface. Ethanol makes the Si surface hydrophilic and helps the etch solution enter the pores. This was very important for the lateral homogeneity and uniformity of the pores.

There is a critical current $J_{\mathrm{PS}}$, which is the upper limit of the current density to obtain porous $\mathrm{Si}$. The HF concentration determines the critical current, $J_{\mathrm{PS}}$. The critical current is obtained using eq. (1) as follows. ${ }^{(6)}$

$$
J_{\mathrm{PS}}=C c^{3 / 2} \exp \left(\frac{-E_{\mathrm{a}}}{K T}\right)
$$




$$
\begin{gathered}
C=3.3 \times 10^{5} \mathrm{~mA} / \mathrm{cm}^{2} \mathrm{wt} \% \\
c=(\mathrm{HF} \mathrm{wt} \%)^{-3 / 2} \\
E_{\mathrm{a}}=343 \mathrm{meV}, \text { activation energy } \\
T: \text { Temperature in Kelvin }
\end{gathered}
$$

Percent porosity is calculated from eq. (2) and is defined as the fraction of voids inside the porous layer vs the starting silicon. It involves the measurement of the starting weight of the sample and its weight after etching.(7)

$$
P(\%)=\frac{\left(M_{1}-M_{2}\right)}{\left(M_{1}-M_{3}\right)}
$$

$M_{1}, M_{2}$, and $M_{3}$ are the weights of the wafer before the electrochemical etch, after the electrochemical etch, and after the porous layer has been removed, respectively. The removal is made by dipping for a few minutes in an aqueous solution of $\mathrm{KOH}(3 \%$ in volume), which results in the selective removal of the porous Si layer without reacting with the bulk crystalline silicon.

Table 1 summarizes the experimental conditions of this investigation and the work done in ref. 1. The ethanol concentration in the etch solution was increased from 50 to $60 \%$ and the DI concentration was decreased from 25 to $15 \%$. These changes were designed to increase the $\mathrm{pH}$ of the etch solution and yield a better wetting of the Si surface.

The $40 \%$ aqueous HF acid solution was replaced with a $60 \%$ aqueous HF acid solution. With a higher HF concentration, the range over which the current density can be varied is wider and vice versa.

For the $60 \%$ aqueous $\mathrm{HF}$ acid solution and etch temperature of $35^{\circ} \mathrm{C}$, the critical current value, $J_{\mathrm{PS}}$, was calculated from eq. (1) to be $48.8 \mathrm{~mA} / \mathrm{cm}^{2}$. With regards to the pores' geometry, it should be noted that the pore's diameter must not be too small to prevent the penetration of the etch solution into silicon (which yields shallow pores) and must not be too large to compromise the sharpness of the pores at the bottom. In this research, the optimum current density was determined to be $46 \mathrm{~mA} / \mathrm{cm}^{2}$, which is below the critical value. To prevent a reduction in the percent porosity due to the increase in the current density, the compositions of the etch solution were changed from (HF:ethanol: DI $)=(25 \%: 50 \%: 25 \%)$ to $(25 \%: 60 \%: 15 \%)$.

Table 1

Experimental conditions of this investigation and the work done in ref. 1.

\begin{tabular}{lcccccc}
\hline $\begin{array}{l}\text { Important } \\
\text { parameters }\end{array}$ & Orientation & $\begin{array}{c}\text { Resistivity } \\
(\Omega \cdot \mathrm{cm})\end{array}$ & $\begin{array}{c}T \\
\left({ }^{\circ} \mathrm{C}\right)\end{array}$ & $\begin{array}{c}\text { Time } \\
(\mathrm{s})\end{array}$ & $\begin{array}{c}\text { Current density } \\
\left(\mathrm{mA} / \mathrm{cm}^{2}\right)\end{array}$ & $\begin{array}{c}\text { (HF:ethanol:DI) } \\
\text { solution }\end{array}$ \\
\hline $\begin{array}{l}\text { Porous sample in } \\
\text { this research }\end{array}$ & $\langle 100\rangle \mathrm{n}-\mathrm{Si}$ & $3.6-5.4$ & 35 & 1800 & 46 & $\begin{array}{c}(25 \%: 60 \%: 15 \%) \\
60 \% \text { aqueous HF acid } \\
(25 \%: 50 \%: 25 \%)\end{array}$ \\
$\begin{array}{l}\text { Porous sample in } \\
\text { ref. } 1\end{array}$ & $\langle 100\rangle \mathrm{n}-\mathrm{Si}$ & $13-33$ & 45 & 1200 & 50 & \begin{tabular}{c}
$(25 \%$ aqueous HF acid \\
\hline
\end{tabular}
\end{tabular}


The etch time was increased from 20 to 30 min to increase the depth of the pores. Longer etch times lead to thicker porous layers. The etch temperature was reduced from 45 to $35^{\circ} \mathrm{C}$ to reduce the critical current as evident from eq. (1). Such experimental conditions resulted in $76 \%$ porous samples as calculated from eq. (2). The porosity level was $70 \%$ in ref. 1 .

To plate $\mathrm{Pt}$ on $\mathrm{Si}$, $\mathrm{Pt}$ was electrodeposited into the pores using a solution containing $\mathrm{H}_{2}\left(\mathrm{PtCl}_{6}\right): 6 \mathrm{H}_{2} \mathrm{O} 4 \mathrm{~g} / \mathrm{L},\left(\mathrm{NH}_{4}\right)_{2} \mathrm{HPO}_{4} 20 \mathrm{~g} / \mathrm{L}$, and $\mathrm{Na}_{2} \mathrm{HPO}_{4} 100 \mathrm{~g} / \mathrm{L}$ at $90^{\circ} \mathrm{C}$. Electrodeposition was performed by applying $20 \mathrm{~mA}$ of current for $45 \mathrm{~min}$, which deposited a thick Pt layer into the pores. The samples were subsequently annealed at $250^{\circ} \mathrm{C}$ for $20 \mathrm{~min}$ followed by another anneal at $550^{\circ} \mathrm{C}$ for $40 \mathrm{~min}$ to form PtSi silicide. The unreacted $\mathrm{Pt}$ was then removed using a standard solution of $\mathrm{HCl}+\mathrm{HNO}_{3} \cdot{ }^{(5,8)}$ Connections were fabricated to the PtSi layer and to the substrate. The samples were tested in air and under an ultrahigh vacuum in a chamber system with a volume of $150 \mathrm{~cm}^{3}$ equipped with a turbomolecular pump. For tests in air, the chamber pressure was first lowered to $10^{-3}$ Torr and then the selected gases were allowed inside the chamber to the predetermined pressure. Air was then let in through an air valve to increase the chamber pressure to the atmospheric pressure. The chamber was then isolated.

\section{Results and Discussion}

An SEM image of a sample prepared in this investigation along with its experimental conditions is provided in Fig. 1. The pores' size (diameter on top) is about $15 \mu \mathrm{m}$ and their depth is about $25 \mu \mathrm{m}$. The pore size, depth, and distribution were uniform and reproducible across the samples. The pores' size and depth in ref. 1 were about 2 and 10 $\mu \mathrm{m}$, respectively.

This investigation as well as other research studies such as the work done in ref. 8 show that the porosity level, geometry, and microstructure of pores depend on the

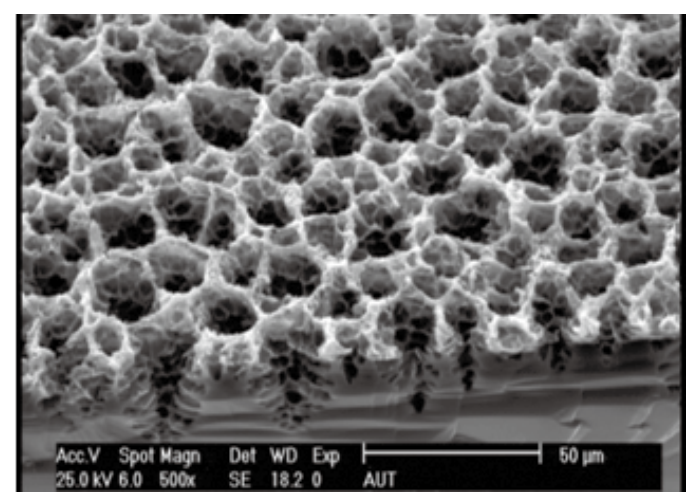

Fig. 1. SEM image of a porous sample in this investigation: $T=35^{\circ} \mathrm{C}, t=1800 \mathrm{~s}, J=46 \mathrm{~mA} /$ $\mathrm{cm}^{2}$, and $(\mathrm{HF}:$ ethanol:DI $)=(1.25: 3: 0.75)$. The pore diameters and depth are about 15 and $25 \mu \mathrm{m}$, respectively. 
anodization conditions. These conditions include HF concentration, current density, wafer type and resistivity, anodization duration, illumination (required for n-type silicon and semi-insulating $\mathrm{p}$-type silicon), temperature, and $\mathrm{pH}$ of the solution.

Under the experimental conditions used in this investigation, the porosity level decreases at the current density of about $15 \mathrm{~mA} / \mathrm{cm}^{2}$ and increases with increasing current density beyond this point (Fig. 2). The decrease in the porosity level at $15 \mathrm{~mA} / \mathrm{cm}^{2}$ can be attributed to the onset of electropolishing. ${ }^{(9)}$

Figure 3 illustrates the effects of current density, HF concentration, and $\mathrm{pH}$ of the solution (due to ethanol) on the pores' structure for a $60 \%$ aqueous HF acid solution. The pore's size increases with increasing current density. To obtain a high porosity level and large pores at a high current density, a higher percentage aqueous HF acid solution was needed. The pore formation is directly proportional to the $\mathrm{pH}\left(\mathrm{OH}^{-}\right.$concentration $)$ of the etch solution.

The reverse bias $I-V$ characteristics of one of the samples are provided in Fig. 4 in air under atmospheric pressure and under vacuum. The sensor fabricated in this research shows a better selectivity between air and vacuum as compared with ref. 1. For instance, if $I=10 \mathrm{~mA}$ is arbitrarily taken as the reference current, $\Delta V=3.8 \mathrm{~V}$ in this research, whereas $\Delta V=1.1 \mathrm{~V}$ for the work done in ref. 1 , where $\Delta V$ is the difference in the breakdown voltages between vacuum and the air.

To analyze the effect of a gas with a dipole moment on the $I-V$ behavior of the Schottky diode sensor, the chamber was pumped down and a mixture of argon (Ar) and $\mathrm{CO}$ with a $\mathrm{CO}$ concentration of $450 \mathrm{ppm}$ in Ar was allowed into the chamber to raise the pressure to 10 Torr. The resultant $I-V$ characteristics are depicted in Fig. 5. The minimum detectable $\mathrm{CO}$ concentration in Ar was $450 \mathrm{ppm}$ for our sensor, whereas for the sensor in ref. 1, it was $500 \mathrm{ppm}$. This indicates a $10 \%$ improvement in the sensitivity to $\mathrm{CO}$ in $\mathrm{Ar}$ of the sensor presented in this investigation.

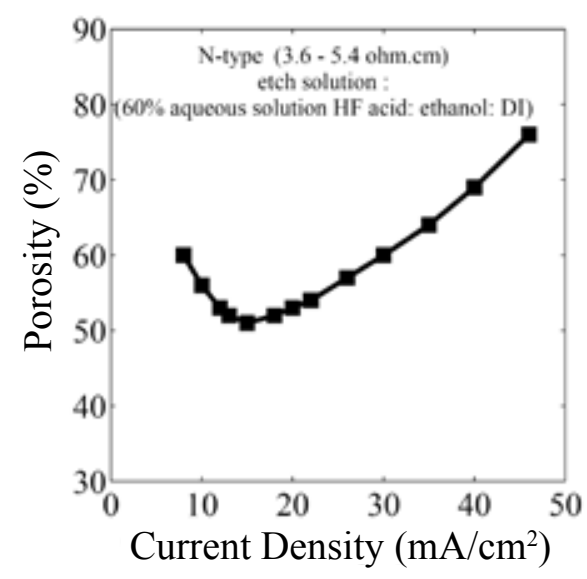

Fig. 2. Si percent porosity as a function of current density. 


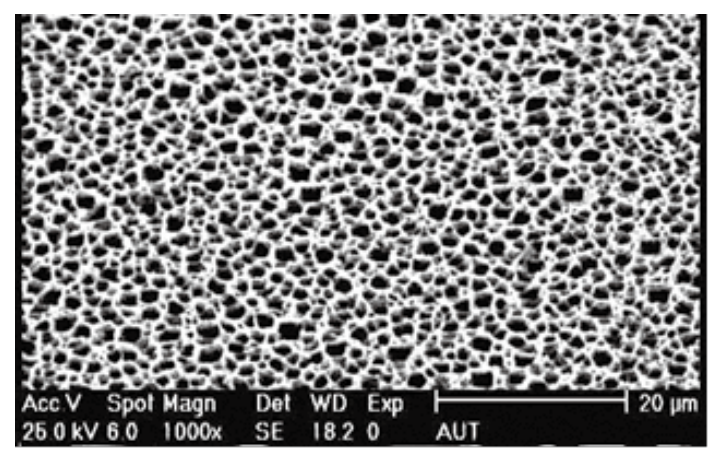

(a)

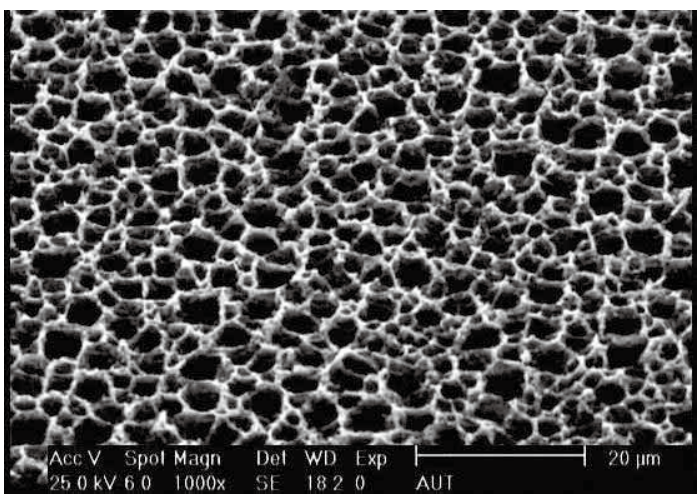

(c)

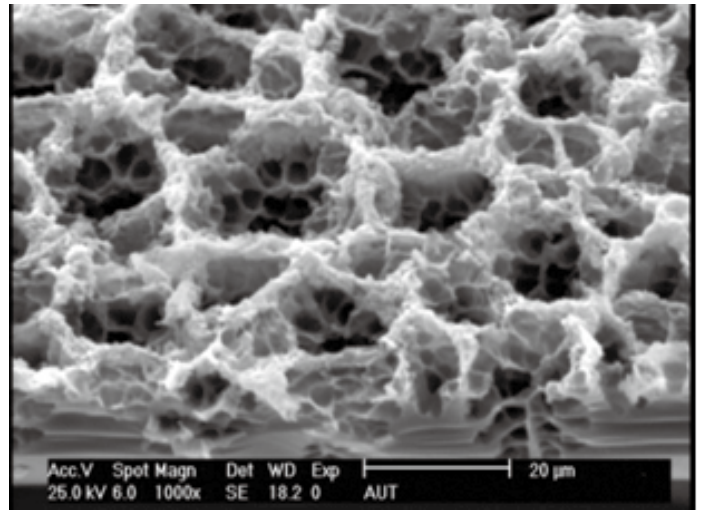

(b)

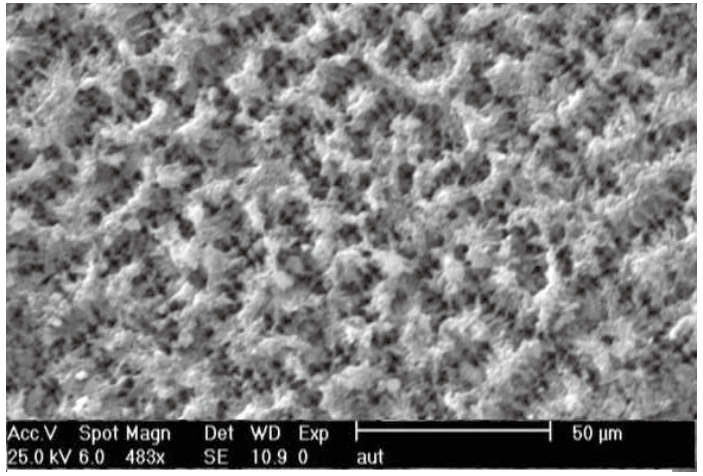

(d)

Fig. 3. Effects of current density, HF concentration, and $\mathrm{pH}$ of solution due to ethanol on porosity and pore size for $60 \%$ aqueous $\mathrm{HF}$ acid solution: (a) $T=35^{\circ} \mathrm{C}, J=35 \mathrm{~mA} / \mathrm{cm}^{2}$, and (HF:ethanol: DI) $=(1.25: 3: 0.75)$; (b) $T=35^{\circ} \mathrm{C}, J=46 \mathrm{~mA} / \mathrm{cm}^{2}$, and (HF:ethanol:DI) $=(1.25: 3: 0.75)$; (c) $T=35$ ${ }^{\circ} \mathrm{C}, J=35 \mathrm{~mA} / \mathrm{cm}^{2}$, and (HF:ethanol:DI) $=(1.25: 2.5: 1.25)$; and (d) $T=35^{\circ} \mathrm{C}, J=35 \mathrm{~mA} / \mathrm{cm}^{2}$, and $(\mathrm{HF}:$ ethanol:DI) $=(1: 3: 1)$. (a) and (b), influence of current density; (a) and (d), influence of HF concentration; and (c) and (d), influence of $\mathrm{pH}$ of the solution due to ethanol.

Figure 6(a) shows the sensitivity of the sensor presented in this research to $\mathrm{CO}$ concentrations in air with the humidity of around $15 \%$. Figure $6(\mathrm{~b})$ summarizes the change in the diode's breakdown voltage as a function of the $\mathrm{CO}$ concentration in air at an arbitrary reverse bias current level of $10 \mathrm{~mA}$. The delta $V(\Delta V)$ values are calculated with respect to air. It is clear that the diode responds to $80 \mathrm{ppm} \mathrm{CO}$ in air. For ref. 1, the minimum $\mathrm{CO}$ concentration was $100 \mathrm{ppm}$. The sensor fabricated in this investigation 

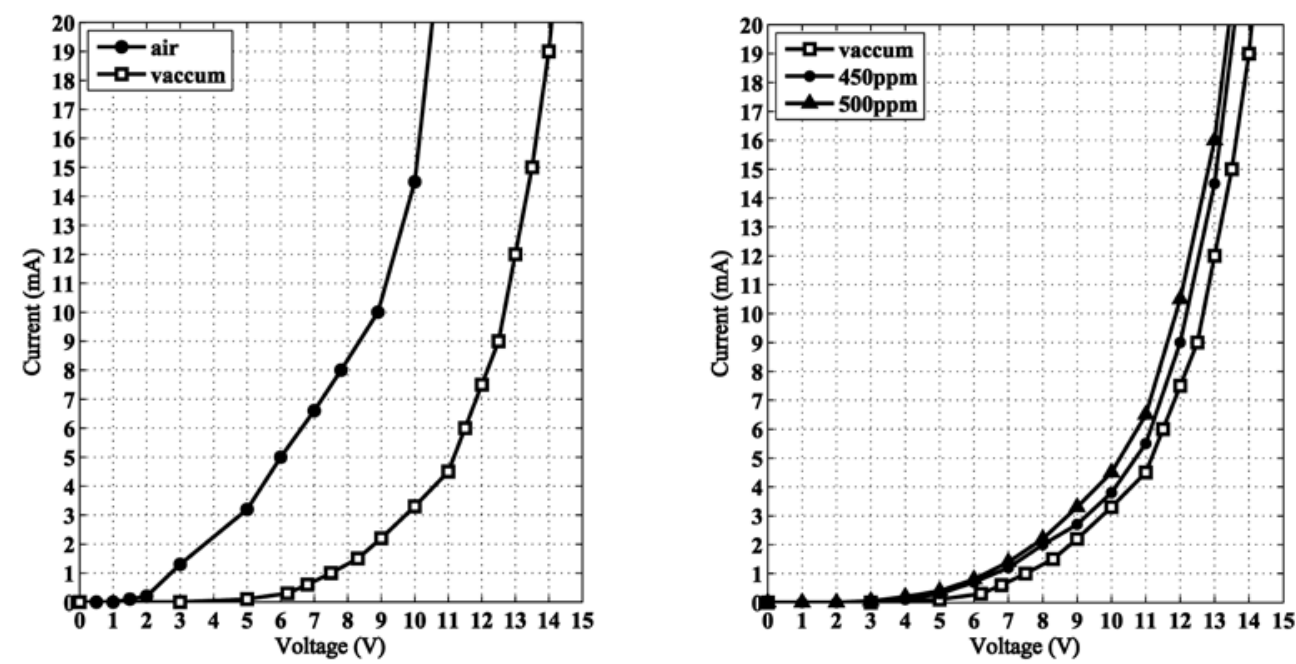

Fig. 4 (left). Reverse bias $I-V$ characteristics obtained in air at atmospheric pressure and under vacuum ( $p=10^{-4}$ Torr) at room temperature.

Fig. 5 (right). $I-V$ curves for vacuum and $\mathrm{CO}$ in vacuum.

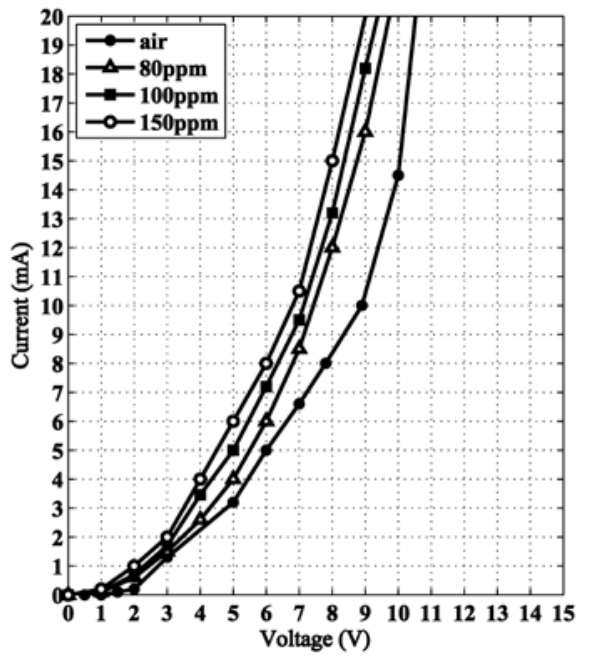

(a)

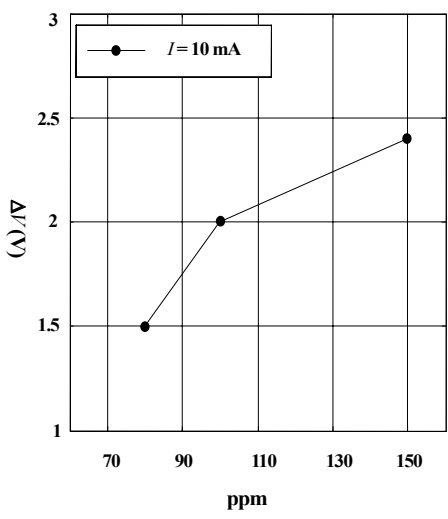

(b)

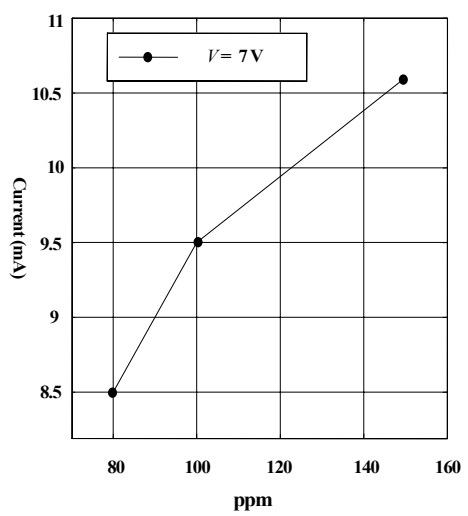

(c)

Fig. 6. (a) $I-V$ characteristics of sensors in this investigation in relation to $\mathrm{CO}$ concentrations in air. (b) Variations in the diode's breakdown voltage as a function of CO concentration in air at an arbitrary current level of $10 \mathrm{~mA}$. (c) Diode's reverse bias current as function of CO concentration in air at an arbitrary reverse voltage level of $7 \mathrm{~V}$. 
shows improvement in its sensitivity to $\mathrm{CO}$ in air by $20 \%$. Figure 6(c) illustrates the diode's reverse bias current as a function of the $\mathrm{CO}$ concentration in air at an arbitrary reverse bias voltage of $7 \mathrm{~V}$. The $\Delta I \approx 1 \mathrm{~mA}$ between 80 and $100 \mathrm{ppm}$ and is about the same between 100 and $150 \mathrm{ppm} \mathrm{CO}$ in air. The diode's current variation is very large between the $\mathrm{CO}$ concentrations used in this experiment and no signal amplification was used. This and the large $\Delta V$ values show the possibility that the diode can respond to much smaller concentrations of $\mathrm{CO}$ in air if the porosity level and pores' geometry are optimized.

The sensitivity of our PtSi sensor to a gas with no dipole moment such as $\mathrm{CO}_{2}$ is illustrated in Fig. 7(a). $\mathrm{CO}_{2}$ is not a polar gas and its presence increases the breakdown voltage. Figure $7(\mathrm{~b})$ summarizes the variations in the diode's breakdown voltage as a function of the $\mathrm{CO}_{2}$ concentration in air at an arbitrary reverse bias current level of 10 $\mathrm{mA}$. The delta $V(\Delta V)$ values are calculated with respect to air. It is clear that the diode responds to $40 \mathrm{ppm} \mathrm{CO}_{2}$ in air. The minimum detectable concentration for the sensor in ref. 1 was $50 \mathrm{ppm}$. Therefore, the sensor fabricated in this research shows an increase in the sensitivity to $\mathrm{CO}_{2}$ concentration by $20 \%$. Figure 7 (c) shows the diode's reverse bias current as a function of the $\mathrm{CO}_{2}$ concentration in air at an arbitrary reverse voltage of 7 $\mathrm{V}$. The $\Delta I=0.812 \mathrm{~mA}$ between 40 and $50 \mathrm{ppm} \mathrm{CO}_{2}$ in air. The diode's current variation is very large between the $\mathrm{CO}_{2}$ concentrations used in this experiment and no signal

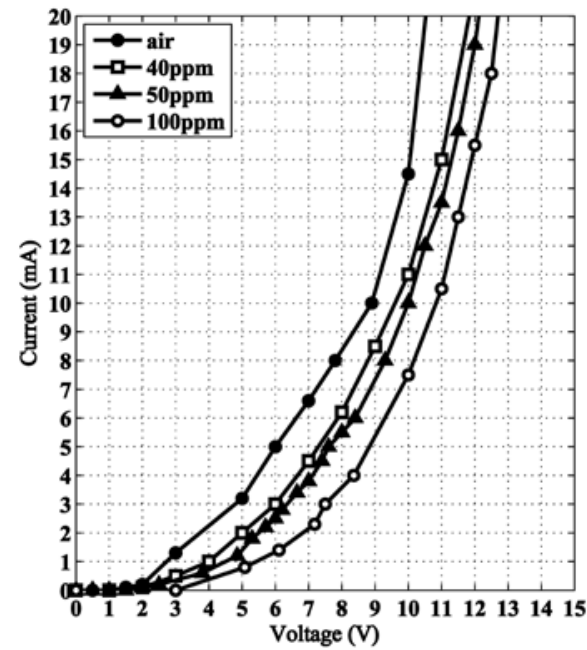

(a)

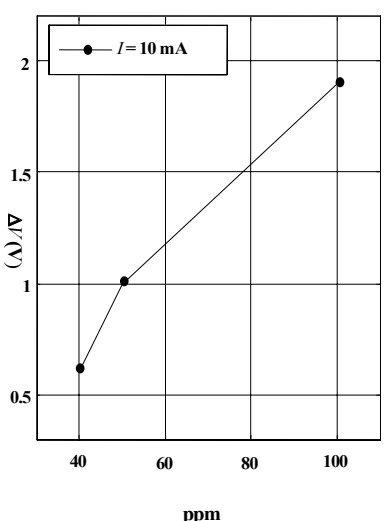

(b)

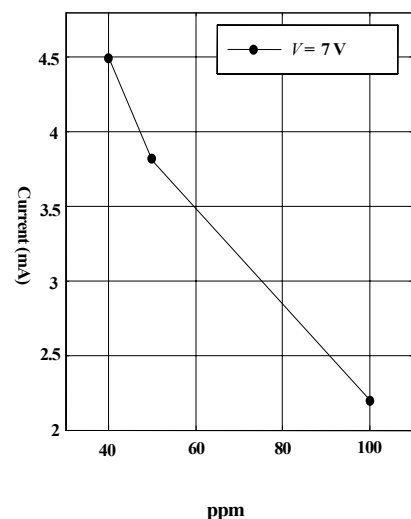

(c)

Fig. 7. (a) $\mathrm{I}-\mathrm{V}$ characteristics of sensors in this investigation in relation to $\mathrm{CO}_{2}$ concentrations in air. (b) Variations in the diode's breakdown voltage as a function of $\mathrm{CO}_{2}$ concentration in air at an arbitrary current level of $10 \mathrm{~mA}$. (c) Diode's reverse bias current as function of $\mathrm{CO}_{2}$ concentration in air at an arbitrary reverse voltage level of $7 \mathrm{~V}$. 
amplification was used. This and the large $\Delta V$ values are indications that the diode can respond to much smaller concentrations of $\mathrm{CO}_{2}$ in air if the porosity level and pores' geometry are optimized. In vacuum, the $\mathrm{CO}_{2}$ presence did not appreciably change the breakdown voltage.

The increase in the sensitivity of the sensors fabricated in this investigation can be attributed to large increases in the electric field in the depletion region between $\mathrm{Pt}$ and $\mathrm{Si}$ at the bottom of pores. A change in the strength of the electric field results in a corresponding change in the $I-V$ characteristics. This can be attributed to the deeper, larger, and sharper pores' geometries that were fabricated in this research. This is a physical phenomenon that can occur at room temperature.

The junctions are sensitive to a gas only when the gas concentration inside pores is larger than a threshold concentration, such that the produced electric field due to the physical presence of the gas molecules inside pores is large enough to affect the Schottky reverse bias voltage. The porosity level and pores' geometry have a significant impact on the total produced electric field. Hence, a PtSi/porous n-Si Schottky diode can respond to smaller concentrations of the gases if the porosity level and pores' geometry are optimized.

Furthermore, with regard to the long-term stability and reproducibility of the PtSi/ porous $\mathrm{Si}$ gas sensors, our experiments have proved the sensors characteristics and behaviors to be reproducible and stable. Several samples of similar geometries were tested several times and over an extended period of time (i.e., 3 months apart) and similar data were obtained for them.

\section{Conclusions}

In this investigation, $\mathrm{PtSi}$ /porous n-Si Schottky diode gas sensors on $\langle 100\rangle$ n-type $\mathrm{Si}$ wafers were fabricated and their sensitivity to concentrations of certain polar gases such as $\mathrm{CO}$ and nonpolar gases such as $\mathrm{CO}_{2}$ were investigated at room temperature and were compared with experimental data reported by others. The samples could be fabricated reproducibly.

The PtSi/porous n-Si Schottky junctions fabricated in this research exhibit a breakdown-type $I-V$ behavior at low reverse bias voltages $(3-6 \mathrm{~V})$. This is due to very large fringing electric fields (i.e., $10^{5}-10^{6} \mathrm{~V} / \mathrm{cm}$ ) that are developed at the sharp edges particularly at the bottom of pores. The presence of certain gases inside the pores changes the electric field distribution and magnitude and shifts the breakdown voltages of the diodes as a function of the gas concentrations inside the pores. Sensitivity is enhanced when the produced electric field due to the physical presence of the gas molecules inside pores is large enough to affect the Schottky reverse bias voltage. The sensors fabricated in this investigation were able to sense $80 \mathrm{ppm} \mathrm{CO}$ gas and $40 \mathrm{ppm}$ $\mathrm{CO}_{2}$ gas in air, which were about $10-20 \mathrm{ppm}$ or $\sim 20 \%$ smaller than those reported in ref. 1. The diode's breakdown voltage variations and current variations were very large between different $\mathrm{CO}$ concentrations and between different $\mathrm{CO}_{2}$ concentrations used in this experiment and no signal amplification was used. These are indications that the diode can respond to much smaller concentrations of $\mathrm{CO}$ and $\mathrm{CO}_{2}$ in air if the porosity level 
and pores' geometry are optimized. High porosity, effective area, pore dimensions, and sharp edges were determined to be the key factors in improving the sensitivity of these sensors. These sensors can operate at room or lower temperatures, which could make these sensors useful in certain low-temperature applications. The pore size and depth can provide us with a certain degree of selectivity in detection, since large molecules may not be able to replace air or other gas molecules inside smaller pores. With regard to the long-term stability and reproducibility of the $\mathrm{PtSi}$ /porous $\mathrm{Si}$ gas sensors, our experiments have proved the sensors characteristics and behaviors to be reproducible and stable.

\section{References}

1 F. Raissi, S. Mirzakuchaki, H. Moheb Jalili and A. Erfanian: IEEE Sens. J. 6 (2006) 146.

2 F. Raissi and R. Farivar: Appl. Phys. Lett. 87 (2005) 164101.

3 S. Khatami, H. Akrami and A. Fattah: Defect Diffus. Forum 316-317 (2011) 81.

4 A. Trinchi, K. Galatsis, W. Wlodarski and Y. X. Li: IEEE Sens. J. 3 (2003) 548.

5 F. Raissi, M. S. Abrishamian and T. Emadi: IEEE Trans. Electron. Device 51 (2004) 339.

6 N. A. Shahny: Fabrication of an Array of PtSi Detector and Imaging with It (Ms.C. dissertation, Dept. Elec. Eng., Univ. Amirkabir, Tehran, 2002).

7 D. Brumhead, L. T. Canham, D. M. Seekings and P. J. Tufton: Electrochem. Acta 38 (1993) 191.

8 F. Raissi and M. Mohtashami Far: IEEE Sens. J. 2 (2002) 476.

9 Z. Gaburro, H. You and D. Babic: J. Appl. Phys. 84 (1998) 6345. 